Revista Destaques Acadêmicos, Lajeado, v. 12, n. 1, 2020. ISSN 2176-3070

DOI: http://dx.doi.org/10.22410/issn.2176-3070.v12i1a2020.2508

http://www.univates.br/revistas

\title{
FATORES MOTIVACIONAIS DAS GERAÇÕES X, Y E Z: UM ESTUDO COM UNIVERSITÁRIOS
}

\author{
William Matheus Eckhardt ${ }^{1}$
}

Resumo: No cenário atual das empresas, percebe-se uma diversidade de pensamentos, ideias e fatores que motivam o trabalhador. Estes comportamentos, muitas vezes, podem estar ligados às características de cada geração atuante no mercado de trabalho. Diante disso, esta pesquisa teve como objetivo identificar os fatores motivacionais dos universitários das gerações X, Y e Z, do Centro de Gestão Organizacional (CGO), da Universidade do Vale do Taquari - Univates, com base em um questionário elaborado pelo autor e disponibilizado para o público-alvo. O estudo foi realizado através de uma pesquisa descritiva, a qual teve abordagem quantitativa, com 240 respondentes. Após a coleta dos dados, estes foram tabulados e analisados por meio de planilhas eletrônicas do programa Microsoft Excel e pelo programa SphinxV5. Ao final do estudo, conclui-se que os resultados obtidos foram importantes, entre eles estão a identificação e a comparação dos principais fatores motivacionais, de acordo com cada geração pesquisada. Além disso, destaca-se o fator "Ambiente de trabalho prazeroso e inovador, no qual possa expor suas ideias e oportunidades de testá-las" como o de maior importância, em grau 5, para a motivação dos três grupos geracionais pesquisados. Com isso, o estudo deverá auxiliar as empresas da região nos processos de tomada de decisão, de acordo com as características de cada grupo geracional existente em seu cenário organizacional.

Palavras-chave: Fatores motivacionais. Gerações. Motivação. Trabalhadores.

\section{INTRODUÇÃO}

No atual cenário de gestão de pessoas, um grande desafio das empresas e, principalmente, da área de recursos humanos, é identificar os fatores que motivam os colaboradores e, a partir disso, definir as ações que devam ser adotadas para atraí-los e mantê-los motivados, diante da diversidade de gerações e suas diferentes formas motivacionais.

Motivar uma pessoa não é uma tarefa fácil, conforme aponta Abrantes (2012), afirmando que, quando motivados, os funcionários tendem a ser mais

1 Graduado do Curso de Administração de Empresas, da Universidade do Vale do Taquari UNIVATES, Lajeado/RS. Gerente Comercial. E-mail: wme.william@gmail.com. 
criativos e podem alcançar melhores resultados. As ações tomadas pelas empresas para motivar os seus colaboradores tendem ser recebidas de formas diferentes, de acordo com o grupo geracional no qual o colaborador esteja alocado, sendo esta uma realidade que deve ser notada pelos setores de gestão de pessoas.

Cada geração apresenta aspectos peculiares, o que, em alguns casos, já está sendo notado pelas empresas. Tendo em vista essas mudanças, as análises sobre as atitudes de cada empregado devem se manter atentas às características específicas de cada geração de trabalhador e não somente ao ambiente disponibilizado para o seu desenvolvimento (VELOSO et al., 2011, VELOSO; DUTRA; NAKATA, 2008).

Desse modo, o presente estudo objetiva identificar os fatores motivacionais dos universitários das gerações X, Y e Z, do Centro de Gestão Organizacional (CGO), da Universidade do Vale do Taquari - Univates, situada em Lajeado/RS. Para atingir o objetivo geral do estudo e responder o problema de pesquisa definido, "como identificar quais são os fatores motivacionais dos universitários das gerações $\mathrm{X}, \mathrm{Y}$ e Z", foram elaborados os seguintes objetivos específicos: (i) identificar o perfil dos respondentes; (ii) descrever os fatores motivacionais das gerações $\mathrm{X}, \mathrm{Y}$ e Z; (iii) comparar os fatores motivacionais de acordo com cada geração. $\mathrm{O}$ estudo deverá contribuir com as empresas da região em seus processos de tomada de decisão, considerando os grupos geracionais presentes em seus ambientes.

Assim, após esta introdução, é abordada a revisão teórica sobre motivação, fatores motivacionais, gerações X, Y e Z e gestão de pessoas, seguida dos procedimentos metodológicos, da apresentação e análise dos resultados, da conclusão e das referências bibliográficas.

\section{FUNDAMENTAÇÃO TEÓRICA}

\subsection{Motivação}

Com a Revolução Industrial (1760 a 1860) e, por conseguinte, o surgimento das indústrias, a preocupação dos empresários passou a ser o alto nível de produtividade da fábrica. Segundo Maximiano (2017), um dos problemas de gestão das fábricas desta época eram as etapas de recrutar, treinar e manter os trabalhadores motivados.

Neste período, Robert Owen apud Maximiano (2017) realizou uma experiência que ofereceu benefícios aos trabalhadores das empresas e provou aos proprietários que eles poderiam motivar os trabalhadores usando atrativos com características mais humanizadas.

Passado o período inicial da Revolução Industrial, surgem os estudiosos e os cientistas preocupados com a motivação das pessoas e com o comportamento dos operários das empresas. Isso ficou evidente no começo 
dos anos 1930, segundo Marras (2011), através do estudo de Hawthorne, realizado nos Estados Unidos, que tinha como objetivo analisar a relação entre a intensidade da iluminação do local de trabalho e a eficiência dos operários, medida através da produção obtida. Esta foi considerada como o ato inicial de estudo específico em comportamento e processo motivacional de trabalhadores nas indústrias.

O ponto central dos estudos sobre motivação, segundo Banov (2013), é identificar por quais motivos as pessoas tomam atitudes de formas divergentes, o que faz acreditar que atitudes direcionadas estão ligadas a estímulos de motivação. Para buscar melhorar os níveis de quantidade e de qualidade da produtividade, Abrantes (2012) afirma que a motivação é um fator de segredo para planejamentos de uma organização no nível operacional.

A motivação das pessoas se torna uma preocupação visível para a organização, na percepção de Bergamini (2008), visto que até mesmo o fato de se abster de fazer algo é um exemplo de motivação para o indivíduo.

Manter os trabalhadores motivados e focados para realizar o trabalho da melhor forma é um grande desafio para os administradores de empresas, visto que cada trabalhador possui formas diferentes de se motivar. Para Abrantes (2012), um ambiente no qual os trabalhadores se sintam confortáveis, respeitados e que possam participar com suas opiniões, favorece a motivação dos indivíduos, devendo também resultar em um aumento da criatividade, e, por consequência, no alcance de melhores resultados de produtividade. Visto isso, cabe aos administradores considerar o fator humano como parte importante da empresa, procurando conhecer as necessidades e os fatores motivacionais que podem contribuir para melhoria dos desempenhos individual e organizacional.

\subsection{Teorias sobre fatores motivacionais}

Na década de 1950, segundo Robbins (2010), foram desenvolvidas as primeiras pesquisas e teorias sobre motivação nas empresas. A seguir, destacamse alguns dos conceitos mais conhecidos sobre motivação dos trabalhadores, divididos em teorias de conteúdo e de processo.

\subsubsection{Teoria da hierarquia das necessidades}

Uma das mais conhecidas teorias de motivação humana, segundo Robbins (2010), foi desenvolvida pelo psicólogo norte-americano Abraham H. Maslow, que, após observar e analisar o comportamento das pessoas, concluiu que o ser humano possui diversas necessidades que devem ser supridas e estabeleceu, de forma organizada, uma hierarquia de prioridades. Para facilitar a compreensão da Teoria de Maslow, utiliza-se uma pirâmide, na qual se apresentam as necessidades de forma sequencial (Figura 1). Esta também demonstra, pelo tamanho de cada área, a devida importância e a dificuldade de se atingir determinada necessidade. 
As necessidades foram divididas em duas categorias: as primárias, consideradas de nível inferior e que são satisfeitas de forma externa, como as necessidades fisiológicas e de segurança; e as secundárias, classificadas como de nível superior, que são atendidas de forma intrínseca, como as necessidades sociais, de estima e de autorrealização.

Figura 1 - A pirâmide de Maslow

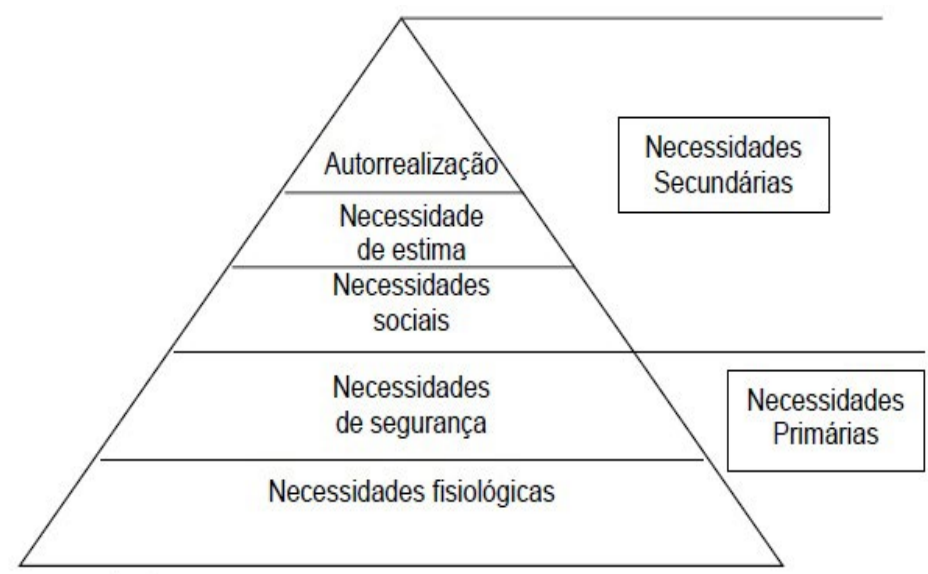

Fonte: elaborada pelo autor, baseada em Banov (2013)

No primeiro andar da pirâmide de Maslow (Figura 1), segundo Banov (2013), encontram-se as principais necessidades fisiológicas dos seres humanos, as quais incluem a alimentação, o sexo, o abrigo e as demais necessidades relacionadas à sobrevivência do ser humano. A mesma autora complementa que, no segundo andar, localizam-se as necessidades de segurança, como proteção diante de danos emocionais e físicos, ou seja, as pessoas devem se sentir seguras sobre os ambientes físico, psíquico e profissional. Estas duas primeiras necessidades integram a categoria das necessidades primárias. Para Banov (2013), somente quando a necessidade anterior for suprida, de forma total ou parcial, almeja-se o nível de uma necessidade posterior da pirâmide.

Na sequência da pirâmide, localizam-se as necessidades secundárias, onde percebem-se três níveis. As necessidades sociais, voltadas para a participação do indivíduo em um grupo, como a amizade e a afeição. As necessidades de estima, relacionadas ao fato de ser reconhecido e valorizado e ter prestígio, como, por exemplo, assumir um cargo de chefia na empresa. No topo da pirâmide, se encontra a necessidade de autorrealização, a qual pode ser considerada como a necessidade mais elevada de um ser humano, que inclui o crescimento do indivíduo como tal, o autodesenvolvimento e, também, se existe ou não prazer pela atividade exercida. 
A Teoria das Necessidades, elaborada por Maslow, aponta se o trabalhador estará motivado para realizar uma necessidade ainda não satisfeita, estando no papel dos administradores observar essas demandas. No cenário atual, a Teoria de Maslow é alvo de críticas sobre a ordem da hierarquia das necessidades, conforme aponta Banov (2013), visto que a teoria foi elaborada na sociedade americana, conhecida mundialmente como individualista, sendo assim, em outros tipos de sociedade, a ordem das hierarquias poderia ser diferente.

\subsubsection{Teoria $X$ e Teoria $Y$}

As Teorias X e Y foram lançadas pelo psicólogo Douglas McGregor, depois de Maslow. Foram elaboradas com base em observações de como os funcionários eram tratados por seus gestores. Ao final das observações, McGregor concluiu que os trabalhadores podem ser classificados em dois conjuntos diferentes: por duas maneiras do jeito de "ser" do trabalhador ou conforme duas maneiras do modo de "ver" o trabalhador ao executar suas atividades (ROBBINS, 2010; MARRAS, 2011).

Para McGregor, determinados indivíduos se enquadram no grupo $X$ e outros no grupo $\mathrm{Y}$. Conforme a Teoria $\mathrm{X}$, os funcionários somente realizarão determinada atividade se forem direcionados para tal atividade, pelo fato de não gostarem do trabalho que realizam. Por outro lado, a Teoria Y é aquela que classifica que os trabalhadores possuem gosto pelo trabalho que realizam e, por isso, possuem vontade de executar as atividades da melhor forma e, também, não precisam ser orientados. Conforme Marras (2011), a maneira como a Teoria de McGregor analisa os trabalhadores resulta em impactos nos resultados da organização, uma vez que, para compreender melhor os relacionamentos dentro e fora da empresa, o modo de "ser" e "ver" dos trabalhadores possui certo grau de relevância.

\subsubsection{Teoria dos Dois Fatores}

A Teoria dos Dois Fatores (teoria da higiene e motivação), formada pelo psicólogo Frederick Herzberg, destacou-se pela relevância atribuída para dois conjuntos de necessidades dos trabalhadores: o trabalho executado e o ambiente onde este se realiza. Para Robbins (2010), a Teoria de Herzberg é baseada na satisfação dos trabalhadores relacionada aos fatores intrínsecos e, por outro lado, a insatisfação está ligada aos fatores extrínsecos, denominados como fatores higiênicos. Banov (2013) complementa afirmando que os fatores higiênicos estão relacionados ao ambiente no qual o trabalhador está inserido, sendo possíveis de serem controlados pelo gestor da empresa, mas que, mesmo presentes, não são diretamente relacionados a estar satisfeito. No entanto, a falta deste fator tende a levar o trabalhador à insatisfação. 
Conforme Banov (2013), segundo a Teoria de Herzberg, os fatores de motivação ou intrínsecos estão diretamente ligados ao trabalhador e às atividades por ele desempenhadas e, por serem caracterizados dessa forma, são de controle do próprio trabalhador. Estes fatores não resultam em insatisfação ou desmotivação quando não presentes, mas, quando presentes, resultam em satisfação e em motivação do trabalhador. Marras (2011) afirma, com base na Teoria de Herzberg, que a maior fonte de motivação para o trabalhador se encontra diretamente relacionada ao respectivo trabalho.

Em comparação com a Teoria de Maslow, Banov (2013) associa os fatores higiênicos de Herzberg com os três primeiros níveis da pirâmide de necessidades de Maslow, que são as necessidades fisiológicas, de segurança e as sociais. Em complemento, Banov (2013) afirma que, como medida de prevenção do baixo desempenho dos trabalhadores, a empresa deve controlar os fatores higiênicos. No nível de cima da pirâmide de Maslow, onde se encontram as necessidades de estima e autorrealização, estão relacionados aos fatores motivacionais, de acordo com a Teoria de Herzberg.

Quadro 1 - Comparativo das Teorias de Maslow e Herzberg

\begin{tabular}{|l|c|}
\hline \multicolumn{1}{|c|}{ Teoria de Maslow } & Teoria de Herzberg \\
\cline { 1 - 1 } Necessidade de autorrealização & $\begin{array}{c}\text { Fatores } \\
\text { Motivacionais }\end{array}$ \\
\cline { 1 - 1 } Necessidade de estima & Fatores \\
Necessidades sociais & Higiênicos \\
\cline { 1 - 1 } Necessidades de segurança & Necessidades fisiológicas
\end{tabular}

Fonte: elaborado pelo autor, baseado em Banov (2013)

Segundo Abrantes (2012), duas críticas são pertinentes ao estudo realizado por Herzberg. Sendo a primeira delas pelo fato de que esta analisou todas as pessoas de forma geral, mesmo sabendo que cada pessoa é diferente e possui forma diferente de se motivar e de se satisfazer. A outra crítica é que o estudo realizado considerou apenas o fato de o trabalhador estar ou não satisfeito no trabalho, sem relacionar o nível de satisfação do trabalhador com seu nível de produtividade.

\subsubsection{Teoria de Necessidades}

A Teoria de Necessidades, de David McClelland, está fundamentada em três principais necessidades que servem para o trabalhador manter-se motivado: necessidade de realização, necessidade de poder e necessidade de afiliação. Sobre a necessidade de realização, McClelland apontou que o indivíduo tem por objetivos a excelência, a realização pessoal, de acordo com padrões definidos e, também, de se dedicar para obter sucesso. 
A segunda necessidade está ligada ao poder de saber influenciar as pessoas para que elas tomem atitudes diferentes das que tomariam por si próprias.

Por último, mas não menos importante, está a necessidade de afiliação, que está relacionada ao desejo do indivíduo de possuir bons e favoráveis relacionamentos interpessoais (ROBBINS, 2010).

\subsubsection{Teorias motivacionais de processo}

Após abordar as teorias motivacionais de conteúdo, apresentam-se as teorias motivacionais de processo, que dizem respeito ao papel do indivíduo na organização, ou seja, quando ele opta ou não por realizar determinada atividade de forma racional. As principais teorias motivacionais de processo são a Teoria do Estabelecimento de Objetivos, a Teoria do Reforço, a Teoria da Equidade e a Teoria da Expectativa.

\subsubsection{Teoria do Estabelecimento de Objetivos}

Elaborada no final da década de 60, segundo Robbins (2010), pelo americano Edwin Locke, que baseou seus estudos em identificar a relação de motivação do trabalhador tendo como foco o estabelecimento de objetivos específicos e com certos graus de complexidades para o indivíduo, mas que venham acompanhados de feedback. Este retorno serve como orientação e tende a levar o profissional a realizar melhores rendimentos na execução dos objetivos propostos.

Tornar o objetivo o mais específico possível tende a funcionar como um estímulo interno ao indivíduo, conforme aponta Robbins (2010), afirmando também que a teoria subentende que se o indivíduo está realmente empenhado em realizar o objetivo, não pensará em desistir. Além disso, o comprometimento com o objetivo, as características com a tarefa e a cultura nacional, segundo a Teoria de Locke, são outros três fatores ligados ao objetivo-desempenho.

Esta teoria, segundo Robbins (2010), pode ser colocada em prática pelos gestores por meio da administração por objetivos (APO). Trata-se de um programa que alia objetivos específicos tangíveis e possíveis de verificação, estabelecidos com a decisão participativa, por um determinado período, e acompanhados de feedback de desempenho. Importante observar que a prática da APO pode obter resultados diferentes de acordo com as características da cultura local de cada país.

\subsubsection{Teoria do Reforço}

Destaca-se, que em determinados casos, os trabalhadores que se sentem recompensados ao realizar determinadas atividades, devem repetir a atividade no aguardo de obter outra recompensa. É o que aponta Marras (2011), ao 
abordar a Teoria do Reforço desenvolvida por B. F. Skinner. Nesse caso, os aspectos intrínsecos do indivíduo são desconsiderados. Conforme Robbins (2010), as atitudes tomadas pelo indivíduo são reflexos dos reforços obtidos e, quando positivamente reforçado, o indivíduo tende a estar motivado para que tal atividade seja repetida.

Os estudos realizados por Skinner sobre o condicionamento operante do indivíduo estão expostos na Teoria de Behaviorismo, a qual, segundo Robbins (2010, p. 201), “[...] o comportamento sucede os estímulos de modo relativamente inconsciente". Assim, conforme a Teoria do Reforço, a motivação provém do ambiente externo, conforme complementa Banov (2013), afirmando que esta teoria motivacional já vem sendo utilizada por algumas organizações e que, neste caso, a automotivação e os fatores internos de motivação do indivíduo não são levados em consideração.

\subsubsection{Teoria da Aprendizagem Social}

O processo de aprendizagem do ser humano pode ser obtido também por seguir exemplos de modelos próximos, como chefes, colegas e pais, e por experiências vividas. É o que afirma Robbins (2010), ao citar a Teoria da Aprendizagem Social, de Julian Rotter. O autor aponta que, além disso, pela percepção, também é possível aprender. Conforme Robbins (2010), os estudos desta teoria se basearam na utilização dos modelos de forma fundamental e, para entender a influência sobre o indivíduo, determinaram quatro processos.

O primeiro deles é o de atenção, ou seja, ao manter a atenção em algum modelo que atraia o indivíduo, este tende a ser mais influenciado, o que facilita a aprendizagem. Segundo, tem-se que os processos de retenção expõem que, ao não ter mais o modelo disponível, a aprendizagem varia de acordo com o quanto o indivíduo recorda do ocorrido.

Na sequência encontram-se os processos de reprodução motora, que defendem que o indivíduo tende a realizar determinada atividade conforme modelo exemplificado, ou seja, após verificar e observar novos comportamentos. Por fim, os processos de reforço dão conta que, ao obter recompensa positiva, o indivíduo tende a realizar de forma motivada a ação, conforme o exemplo. Assim, quanto mais reforçada for a recompensa, maior será a atenção do indivíduo para seguir o modelo (ROBBINS, 2010).

\subsubsection{Teoria da Equidade}

A percepção de justiça do indivíduo perante os fatos ocorridos nas organizações é o que fundamenta a Teoria da Equidade, conforme aponta Banov (2013), ao relatar a teoria desenvolvida em 1965, por John Stacey Adams. Os trabalhadores tendem a comparar seus esforços realizados em prol da organização com as recompensas recebidas por eles e, ainda, comparar com o que os seus colegas obtiveram em relação ao esforço e recompensa. É o que 
assinala Robbins (2010), sobre a Teoria da Equidade, complementando que, na empresa, o gênero dos trabalhadores, o tempo na organização, o nível hierárquico e as experiências servem como variáveis moderadoras para as comparações entre colegas de trabalho.

É um sinal de que o indivíduo percebeu a justiça quando doa, ao máximo, seus esforços para a organização e se mantém motivado. Por outro lado, o comportamento de revolta e de insatisfação é resultado de perceber a injustiça na comparação de esforços e recompensas em relação aos outros na organização. $\mathrm{O}$ indivíduo encontra um ponto de equidade após comparar e perceber que existe relação entre os esforços e as recompensas. Por outro lado, além de poder perceber injustiças, o indivíduo pode observar que em determinadas situações as recompensas são exageradas, podendo gerar um sentimento de culpa (ROBBINS, 2010; BANOV, 2013).

Para Robbins (2010), alguns exemplos de que o indivíduo percebeu uma injustiça podem ser notados em algumas situações. Um exemplo é mudar suas ações rotineiras, podendo realizar menor esforço, quando se sentindo injustiçado, e mais esforço, quando recompensado além do esperado. Outro exemplo, é alterar seus métodos de trabalho, podendo produzir com menor qualidade, reconsiderar seu ritmo e interesse em realizar determinada atividade de trabalho baseado na comparação com o colega e definir outra referência de comparação com base nas recompensas obtidas. Por último, deixar o emprego após desistir das injustiças percebidas. As recompensas e, também, a forma como estas são recebidas, são maneiras pelas quais os indivíduos tendem a constatar que as organizações estão sendo justas.

\subsubsection{Teoria da Expectativa}

A Teoria da Expectativa, desenvolvida por Victor Vroom, procura esclarecer os motivos pelos quais alguns trabalhadores se mantêm motivados em suas organizações, enquanto outros não. De acordo com Robbins (2010), a motivação do indivíduo para realizar o esforço necessário de determinada atividade provém do fato de sentir que irá receber recompensas positivas da organização ao obter um resultado satisfatório na avaliação de desempenho, e, assim, satisfazer suas metas pessoais quando as recompensas recebidas coincidirem com seus desejos e necessidades.

Marras (2011) afirma, a partir do modelo de Vroom, que aquilo que os indivíduos aguardam como recompensa, bem como o seu valor, são variáveis determinantes para a motivação deles e proporcionais às respostas dadas na realização das atividades. Para esclarecer a motivação dos indivíduos, a Teoria de Vroom é uma das mais admitidas, segundo Robbins (2010, p. 217). O estudioso complementa, afirmando que as relações esforço-desempenho, desempenho-recompensa e recompensa-metas pessoais são as três relações 
que a teoria enfoca. A Figura 2 apresenta uma esquematização desta afirmação sobre a teoria.

Figura 2 - Teoria da Expectativa

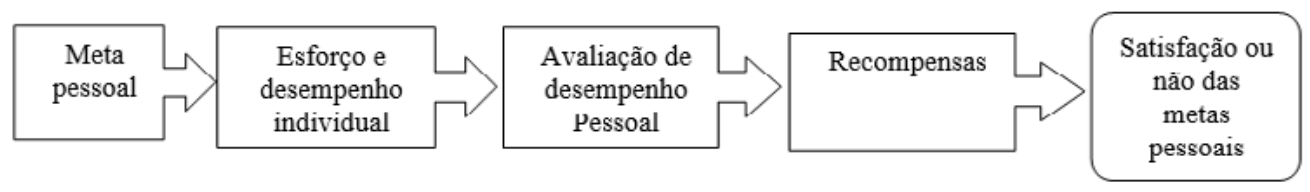

Fonte: elaborada pelo autor, baseada em Robbins (2010).

\subsection{Gerações no mercado de trabalho}

A diversidade de gerações atuantes no mercado de trabalho exige das empresas processos de integração e trabalho para manter os trabalhadores motivados e comprometidos com os objetivos organizacionais. Torna-se claro que as empresas devem identificar à qual geração o colaborador pertence e suas características, a fim de facilitar a inter-relação no ambiente organizacional.

\subsubsection{Geração $X$}

Para Banov (2013), as pessoas nascidas entre 1960 e 1979 são caracterizadas por sua rebeldia, visão convencional e pelo medo de serem demitidas, apesar de serem dedicadas e pragmáticas na realização de tarefas nas organizações. Para este grupo, o fato de gerenciar uma equipe significa comandar, assim como, possuir grande identificação com a organização ao "vestir a camisa da empresa".

Estas pessoas são caracterizadas por serem compulsivas pelo trabalho, princípio adotado por esta geração, tendo como base o termo workaholic (viciado em trabalho), oriundo dos Estados Unidos. Por mais que pessoas viciadas em trabalho sempre existiram, foi neste período que esse modelo se tornou comum, devido às necessidades de cada indivíduo de se doar tanto ao trabalho (OLIVEIRA, 2012).

Quanto ao ambiente de trabalho, preferem que seja mais informal, que não seja caracterizado por uma hierarquia rigorosa e, por se desenvolverem na empresa durante o período do downsizing corporativo, atuam com a desconfiança da perda de seus postos. Isso, de certa forma, impulsionou esse público a buscar uma melhora das suas habilidades, a fim de manterem o emprego, pois perceberam que não basta somente ter lealdade à empresa (VELOSO; DUTRA; NAKATA, 2008). 


\subsubsection{Geração Y}

A geração Y, nascida entre 1980 e 1990, caracteriza-se pelas pessoas realizarem de forma rápida os desafios propostos para, em seguida, obter feedback e se diferencia, também, porque não se baseiam nos padrões utilizados para formar o cenário atual da sociedade.

Por crescerem socializados e familiarizados com o uso das tecnologias, destacam-se por aliar o potencial intelectual com a facilidade diante de ambientes tecnológicos disponíveis no ambiente de trabalho. Isso os difere das gerações anteriores, uma vez que possuem características apreciadas pelos recrutadores das empresas (BANOV, 2013; OLIVEIRA, 2012).

Os jovens da geração $\mathrm{Y}$ possuem algumas características que, segundo Banov (2013), desagradam alguns gestores de empresas, especialmente quando são confiantes demais, imediatistas e desejam evoluir de forma rápida em suas carreiras e empresas, tendo também dificuldade em realizar e cumprir planejamentos de longo prazo.

\subsubsection{Geração Z}

A geração Z pertence ao grupo de pessoas nascidas entre 1990 e 2010, período marcado pelo advento da tecnologia. Iniciaram no mercado de trabalho, em alguns casos, antes mesmo de concluírem seus estudos. Conforme Nascimento et al. (2016), diferentemente das gerações anteriores, as pessoas dessa geração possuem como principais traços a extrema facilidade em estarem sempre conectados com velocidade, a facilidade de diálogo proporcionado pela globalização, desempenham atividades multitarefas e procuram realizar desafios e passar por constantes mudanças. Por estarem acostumados com isso, esperam que o ambiente organizacional também seja assim.

\subsection{O papel da gestão de pessoas}

Com a necessidade de uma melhor gestão dos colaboradores e pelas organizações se encontrarem diante de uma nova realidade, conforme Araújo (2010), a gestão de pessoas chega para suprir as necessidades das organizações no que tange à implantação de melhorias de processos junto às suas equipes. $\mathrm{O}$ mesmo autor afirma que o que move a organização para alcançar os objetivos é o capital humano, sendo o clima organizacional favorável um estímulo a mais para a melhoria dos resultados.

A motivação dos colaboradores, na percepção de Barbieri (2014), resulta em um ponto de diferenciação entre as organizações, juntamente com outras habilidades, como o conhecimento coletivo, a criatividade e a inovação. Com a preocupação das organizações em suprir as necessidades de competitividade, segundo Lapolli (2010), a área de recursos humanos ganhou destaque, visto que 
esta é fundamental para contextualizar as estratégias de alcance dos objetivos da empresa em prol do seu crescimento.

No ambiente organizacional, a diversidade de gerações, na percepção de Banov (2013), tende a contribuir para o desenvolvimento da organização. Para isso, cabe ao gestor de pessoas perceber os modelos de comportamento conforme cada geração e seus modos de serem geridos, respeitando os padrões básicos de cada um, para que não ocorram conflitos.

Este cenário é, de certo modo, complexo, mas essencial, na visão de Oliveira (2012), visto que pode refletir com sucesso na percepção dos fatores necessários para manter os jovens motivados no ambiente de trabalho e, também com isso, há otimização nos processos de geração e de desenvolvimento de novos talentos para a organização.

\section{PROCEDIMENTOS METODOLÓGICOS}

Segundo apresentado por Gil (2012, p. 8), método é o caminho para chegar a determinado fim, sendo este definido de acordo com "o tipo de objeto a investigar e sua classe de proposições a descobrir". Este estudo é classificado como descritivo, pois, segundo Mascarenhas (2012), propõe-se a abordar as características de uma determinada população e, também, o estabelecimento de relações entre as variáveis. Malhotra (2012) afirma que deve ser adotada uma forma clara e específica para a coleta de dados.

A abordagem da pesquisa é quantitativa. De acordo com Mascarenhas (2012), este tipo de pesquisa é caracterizado pela capacidade de generalização dos dados obtidos e a quantificação de dados facilita as conclusões acerca do estudo. O autor afirma que deve ser adotado o uso de técnicas estatísticas, para que o resultado não possua influência do pesquisador e, com isso, se mantenha imparcial.

Como instrumento de coleta de dados, foi elaborado e utilizado um questionário, dividido em duas partes. Na primeira parte, constam questões que buscam identificar o perfil do respondente e, na segunda parte, questões relacionadas aos objetivos específicos do presente estudo.

Evidencia-se que, em algumas questões, foi utilizada a escala de Likert, ou seja, uma escala de 1 a 5, elaborada segundo Gil (2012). Nesta escala, a afirmação de grau 1 significa fatores que considera ter menor importância e 5 aqueles com maior importância, como fator motivacional para o respondente. As questões foram elaboradas com base na literatura de Abrantes (2012), Banov (2013), Bergamini (2008), Oliveira (2012) e Robbins (2010).

Para a definição da população-alvo, utilizou-se o conceito apresentado por Malhotra (2012, p. 271): "a coleção de elementos ou objetos que possuem as informações procuradas pelo pesquisador". Ainda conforme o mesmo autor, esta deve ser definida de forma precisa, para que não ocorram erros. 
A população-alvo foi constituída por acadêmicos da Universidade do Vale do Taquari - Univates, matriculados no semestre 2018/B, em seis disciplinas do Centro de Gestão Organizacional (CGO). As disciplinas foram escolhidas por possuírem, em suas ementas, assuntos de acordo com a temática desta pesquisa e se localizarem em fase média para avançada da grade curricular da graduação. Além dos universitários matriculados nas disciplinas citadas, a Turma I de formandos do CGO no semestre 2018/B, também constituiu a população-alvo, pelo fato dos integrantes estarem em fase final de graduação, o que, subentende-se, que possuem conhecimento sobre o tema abordado. Com base nesses critérios, a população total alcançada foi de 392 alunos matriculados.

A amostra aleatória foi de 240 respondentes $(61,2 \%)$. O tamanho da amostra seguiu a orientação de Santos (2018), que, para alcançar um nível de confiança de $95 \%$ e um erro amostral de $4 \%$, a amostra necessária seria de 238 respondentes.

Para fins de tabulação dos dados, foram utilizados os programas Microsoft Excel e o SphinxV5. Ainda, fez-se uso da análise estatística, a qual, de acordo com Gil (2012), além de contribuir para identificar as características dos dados de forma resumida, facilita a compreensão da existência de relação entre as variáveis. Também, permite que as conclusões possam ser consideradas para além da amostra colocada em pauta no estudo.

\section{APRESENTAÇÃO E ANÁLISE DOS RESULTADOS}

Nesta seção, apresentam-se os resultados obtidos por meio da aplicação da pesquisa e, em seguida, a discussão sobre os resultados apurados.

\subsection{Perfil dos respondentes}

Quanto ao sexo, o perfil dos universitários respondentes abrange 52,5\% homens e 47,5\% mulheres. Em relação ao grupo geracional ao qual pertencem, 51,7\% (124 respondentes) são da Geração Y, 46,7\% (112 respondentes) da Geração Z e 1,7\% (4 respondentes) da Geração X. Por se tratar de população universitária, verifica-se maior número de respondentes das gerações $\mathrm{Y}$ e $Z$ e poucos respondentes da geração $X$ (somente 4). Referente ao exercício de atividades profissionais, atualmente $97,1 \%$ estão empregados e $2,9 \%$ estão desempregados.

No que se refere à motivação em relação ao trabalho desenvolvido atualmente ou anteriormente, em caso do respondente estar desempregado, $82,9 \%$ afirmam estarem motivados e $17,1 \%$ afirmam não estarem motivados. Sobre o tempo de atuação na empresa atual, 23,3\% estão um ano ou menos, $28,3 \%$ estão entre dois e três anos, $23,8 \%$ estão de quatro a seis anos e $24,6 \%$ estão seis anos ou mais na mesma empresa. Sobre o exercício de função de coordenação, direção ou liderança, $62,9 \%$ não exercem e $37,1 \%$ exercem. 


\subsection{Fatores motivacionais no ambiente de trabalho de acordo com cada grupo geracional}

A Tabela 1 apresenta as características referentes ao grau de importância dos fatores motivacionais no ambiente de trabalho, conforme cada grupo geracional participante da pesquisa.

Tabela 1 - Características em relação ao grau de importância atribuído pelos participantes da pesquisa aos fatores motivacionais no exercício de suas atividades na empresa, segundo o grupo geracional

\begin{tabular}{l|c|c|c}
\hline Fatores motivacionais & $\begin{array}{c}\text { Geração X } \\
\text { (nascidos } \\
\text { entre os } \\
\text { anos de 1961 } \\
\text { e 1979) }\end{array}$ & $\begin{array}{c}\text { Geração Y } \\
\text { (nascidos } \\
\text { entre os } \\
\text { anos de 1980 } \\
\text { e 1994) }\end{array}$ & $\begin{array}{c}\text { Geração Z } \\
\text { (nascidos } \\
\text { entre os } \\
\text { anos de 1995 } \\
\text { e 2010) }\end{array}$ \\
\hline $\begin{array}{l}\text { O quanto você se sente devidamente } \\
\text { recompensado de acordo com o trabalho realizado } \\
\text { nesta empresa e com isso motivado para seguir } \\
\text { nela. }\end{array}$ & 4,00 & 3,75 & 3,78 \\
\hline $\begin{array}{l}\text { Em relação ao seu dia a dia na empresa e o } \\
\text { trabalho realizado por você, o quanto você se sente } \\
\text { devidamente motivado nesta empresa. }\end{array}$ & 4,00 & 3,87 & 3,71 \\
\hline $\begin{array}{l}\text { Sobre o que se refere às necessidades fisiológicas, } \\
\text { para você, o quão importante para a sua motivação } \\
\text { é o fato da empresa disponibilizar um bom } \\
\text { refeitório para refeições e um lugar confortável } \\
\text { para o intervalo da jornada (almoço). }\end{array}$ & 4,00 & 3,78 & 3,91 \\
\hline $\begin{array}{l}\text { Referente às necessidades de segurança, o fato } \\
\text { de estar trabalhando em um ambiente que te } \\
\text { proporciona segurança física (boas instalações), } \\
\text { psíquica (cobranças e carga horária) e de segurança } \\
\text { profissional (salário compatível com a função), o } \\
\text { quanto estes fatores influenciam na sua motivação. }\end{array}$ & 4,25 & 4,35 & 4,47 \\
\hline $\begin{array}{l}\text { No que se refere aos fatores de necessidades } \\
\text { sociais, trabalhar em uma empresa que você } \\
\text { mantenha um bom relacionamento com colegas, } \\
\text { diretores, líderes e o setor de recursos humanos, o } \\
\text { quanto isso interfere na sua motivação. }\end{array}$ & 4,75 & 4,60 & 4,52 \\
\hline $\begin{array}{l}\text { De acordo com as necessidades de autoestima, } \\
\text { trabalhar numa empresa onde você possui } \\
\text { liberdade para dar sugestões, autonomia para } \\
\text { indicar melhorias no ambiente de trabalho, } \\
\text { acompanhado de reconhecimento profissional, em } \\
\text { que grau isso influencia na sua motivação. }\end{array}$ & 4,75 & 4,50 & \\
\hline $\begin{array}{l}\text { Sobre as necessidades de autorrealização, com } \\
\text { base de que você deseja receber valorização pelo } \\
\text { seu trabalho, acompanhada de oportunidades de } \\
\text { crescimento dentro da empresa, o quanto possuem } \\
\text { influência na sua motivação. }\end{array}$ & 4,75 & 4,58 \\
\hline $\begin{array}{l}\text { Média do bloco } \\
\text { Fonte: elaborada }\end{array}$ & & & \\
\hline & & & \\
\hline
\end{tabular}

Fonte: elaborada pelo autor, com base nos dados da pesquisa (2018)

Observações: os valores da tabela foram calculados de forma ponderada entre os graus 1 a 5 , sendo o grau 1 o de menor importância, e o grau 5, de maior importância. 
Analisando a Tabela 1, nota-se que os respondentes da geração $X$ obtiveram maior média em cinco das seis questões abordadas, totalizando uma média de 4 pontos de um total de 5 possíveis. Em relação às necessidades de segurança, este grupo apresentou a menor média, podendo-se concluir que a motivação se manterá mesmo que a situação estrutural de trabalho oferecida pela empresa não seja das melhores, sendo possível atrelar à definição de Banov (2013), anteriormente citada, de que são pessoas dedicadas e pragmáticas na realização de tarefas. Sobre terem sido o grupo com maior média no que tange a se sentirem recompensados e motivados com o trabalho realizado, é possível contextualizar com a afirmação de Banov (2013), a qual coloca que este grupo possui grande identificação com a organização.

Em segundo lugar, encontra-se o grupo da geração $Z$, com média de 3,78 e, em seguida, o grupo da geração $Y$, com média de 3,75. Estes dois grupos possuem médias muito próximas em todas as questões abordadas na Tabela 1. Com isso, conclui-se que entendem os fatores de motivação com devida similaridade, o que é um ponto a ser analisado pelos gestores das empresas. Mesmo com tamanho avanço das tecnologias e algumas mudanças das formas de trabalho enfrentadas por esses grupos, a percepção de motivação está próxima.

A Tabela 2 apresenta as definições de cada geração sobre a influência ou não da motivação no ambiente de trabalho, de acordo com cada situação informada.

Tabela 2 - Influência na motivação dos participantes da pesquisa, de acordo com a situação informada, segundo o grupo geracional, em percentual

\begin{tabular}{l|c|c|c}
\hline Situação Informada & $\begin{array}{c}\text { Geração X } \\
\text { (nascidos } \\
\text { entre os anos } \\
\text { de 1961 e } \\
\text { 1979) }\end{array}$ & $\begin{array}{c}\text { Geração Y } \\
\text { (nascidos } \\
\text { entre os anos } \\
\text { de 1980 e } \\
\mathbf{1 9 9 4}\end{array}$ & $\begin{array}{c}\text { Geração Z } \\
\text { (nascidos } \\
\text { entre os anos } \\
\text { de 1995 e } \\
\text { 2010) }\end{array}$ \\
\hline $\begin{array}{l}\text { Aumento da motivação com direcionamento do } \\
\text { superior }\end{array}$ & 50,0 & 59,7 & 68,8 \\
\hline $\begin{array}{l}\text { Realização de atividades com motivação porque } \\
\text { gosta do trabalho que faz sem ter que ser } \\
\text { orientado }\end{array}$ & 100 & 84,7 & 82,1 \\
\hline $\begin{array}{l}\text { Aumento de motivação com objetivos específicos } \\
\text { e feedback }\end{array}$ & 100 & 79,8 & 82,1 \\
\hline $\begin{array}{l}\text { Aumento de motivação com elogios e } \\
\text { recompensas }\end{array}$ & 50,0 & 84,7 & 91,1 \\
\hline $\begin{array}{l}\text { Influência na motivação com atitudes inovadoras } \\
\text { de sucesso reconhecidas na empresa }\end{array}$ & 75,0 & 88,7 & 83,0 \\
\hline $\begin{array}{l}\text { Influência na motivação na comparação entre } \\
\text { esforços e recompensas }\end{array}$ & 75,0 & 76,6 & 74,1 \\
\hline $\begin{array}{l}\text { Influência na motivação da recompensa e } \\
\text { valorização }\end{array}$ & 100 & 89,5 & 94,6 \\
\hline
\end{tabular}

Fonte: elaborada pelo autor, com base nos dados da pesquisa (2018)

Observações: os percentuais foram calculados sobre o total de observações de cada coluna. 
Interpretando a Tabela 2, verifica-se que, na primeira situação informada, os participantes da pesquisa afirmam que no seu ambiente de trabalho a motivação aumenta quando realizam uma atividade que é direcionada por algum superior. Este fator é considerado em maior grau para o aumento da motivação para os respondentes da geração $\mathrm{Z}$, com $68,8 \%$ dos participantes. Observa-se, ainda, que esta consideração é comum aos três grupos geracionais que integram a amostra, não havendo diferenças estatísticas significativas em termos de percentuais.

Na situação que apresenta os resultados sobre realizar todas as atividades com motivação porque o respondente gosta do trabalho que faz, sem ter que ser orientado por um superior, pode-se observar que todos os respondentes da geração $X$ realizam com motivação as atividades porque gostam do trabalho que realizam. Percebe-se que este fator foi comum aos três grupos geracionais pesquisados, nos quais foram obtidos, no mínimo, $82 \%$ de afirmações positivas. Com isso, é possível concluir que, para os três grupos geracionais, a maioria dos respondentes realiza as atividades com motivação porque gosta da atividade realizada, sem ter que ser orientada por algum superior.

Quando questionados sobre o aumento de motivação para realizar determinada atividade com objetivos específicos acompanhada de feedback, destaca-se o grupo da geração X, com 100\% de concordância, seguido dos respondentes das gerações $\mathrm{Z}$ e Y. Na quarta linha, ao serem questionados sobre o aumento de motivação para realizar determinada atividade, por receber pequenos estímulos como elogios ou recompensas, destacou-se o grupo da geração $Z$, com 91,1\%, acompanhado dos respondentes da geração $Y$, com $84,7 \%$, e da geração $X$, com $50 \%$ de afirmações positivas.

Ao serem questionados sobre a influência na motivação com a existência de exemplos de atitudes inovadoras de sucesso e reconhecidas na empresa, os três grupos geracionais obtiveram percentuais altos, destacando-se o grupo da geração $Y$, com $88,7 \%$, seguido com proximidade dos respondentes das gerações $Z$, com $83 \%$, e da $X$, com $75 \%$. Sobre a influência da motivação no seu ambiente de trabalho, diante da comparação de seus esforços e de colegas com as respectivas recompensas recebidas na organização, os três grupos pesquisados obtiveram percentuais similares e próximos de $75 \%$.

Sobre a influência na motivação diante do fato de saber que haverá recompensa e valorização após determinada atividade, nota-se que para os três grupos é alto o índice de concordância: geração $X, 100 \%$ dos respondentes; geração $Z, 94,6 \%$; e geração $Y, 89,5 \%$.

Analisando de uma forma geral a Tabela 2, conclui-se que, para as três gerações pesquisadas, as situações externas informadas influenciam, sim, na realização de tarefas com maior motivação no ambiente organizacional, o que é um ponto a ser analisado pelos gestores de equipes em prol da obtenção de melhores desempenhos de suas equipes. 
Ao serem questionados sobre a origem predominante da motivação para realizar as atividades no ambiente trabalho, os resultados estão apresentados na Tabela 3.

Tabela 3 - Tipo de fatores predominantes que refletem a motivação nos participantes da pesquisa no seu ambiente de trabalho para realizar suas atividades no trabalho, segundo o grupo geracional, em percentual

\begin{tabular}{l|c|c|c}
\hline $\begin{array}{c}\text { Tipos de fatores predominantes } \\
\text { na motivação / Grupo geracional }\end{array}$ & $\begin{array}{c}\text { Geração X } \\
\text { (nascidos entre } \\
\text { os anos de 1961 e e } \\
\mathbf{1 9 7 9 )}\end{array}$ & $\begin{array}{c}\text { Geração Y } \\
\text { (nascidos entre } \\
\text { os anos de 1980 e } \\
\mathbf{1 9 9 4 )}\end{array}$ & $\begin{array}{c}\text { Geração Z } \\
\text { (nascidos entre } \\
\text { os anos de 1995 e } \\
\text { 2010) }\end{array}$ \\
\hline Extrínsecos & 0,0 & 32,3 & 43,8 \\
\hline Intrínsecos & 100 & 67,7 & 56,3 \\
\hline Total & $\mathbf{1 0 0}$ & $\mathbf{1 0 0}$ & $\mathbf{1 0 0}$ \\
\hline
\end{tabular}

Fonte: elaborada pelo autor, com base nos dados da pesquisa (2018)

Observações: os percentuais foram calculados sobre o total de observações de cada coluna.

Percebe-se que, em todos os grupos geracionais, grande parte dos respondentes afirma que a motivação possui origem predominantemente intrínseca, destacando-se o grupo da geração X, onde $100 \%$ dos respondentes concorda. A maioria dos respondentes da geração $\mathrm{Y}$ afirma que o tipo de fator predominante na motivação é intrínseco. Quanto aos respondentes da geração $Z$, os resultados estão equilibrados, com leve predominância do fator de tipo intrínseco.

Nas próximas tabelas será apresentada uma análise realizada de acordo com a influência dos fatores motivacionais no ambiente de trabalho, os quais foram disponibilizados nas alternativas e deveriam ser enumerados por ordem de importância entre 5 e 1 , sendo 5 o fator de maior influência e 1 o de menor influência.

As Tabelas 4, 5 e 6 compõem a resolução do objetivo específico (iii) do presente estudo, que é comparar os fatores motivacionais de acordo com cada geração. 
Tabela 4 - Influência por ordem de importância de fatores na motivação para os respondentes da geração $X$, em percentual

\begin{tabular}{|c|c|c|c|c|c|}
\hline \multirow{3}{*}{$\begin{array}{l}\text { Geração } X \\
\text { Fatores de influência na motivação }\end{array}$} & \multicolumn{5}{|c|}{ Grau de importância } \\
\hline & \multicolumn{3}{|c|}{ Maior } & \multicolumn{2}{|c|}{ Menor } \\
\hline & \begin{tabular}{|l|}
5 \\
\end{tabular} & 4 & 3 & 2 & 1 \\
\hline $\begin{array}{l}\text { Ambiente de trabalho prazeroso e inovador, no qual possa } \\
\text { expor suas ideias e oportunidades de testá-las. }\end{array}$ & 75,0 & 25,0 & 0,0 & 0,0 & 0,0 \\
\hline Uma ótima remuneração, que aumente seu poder de compra. & 25,0 & 25,0 & 0,0 & 50,0 & 0,0 \\
\hline $\begin{array}{l}\text { Prestígio por ocupar um bom cargo numa empresa renomada e } \\
\text { conhecida por todos }\end{array}$ & 0,0 & 50,0 & 25,0 & 0,0 & 25,0 \\
\hline $\begin{array}{l}\text { Para mim a motivação é intrínseca, fatores externos não me } \\
\text { influenciam. }\end{array}$ & 0,0 & 0,0 & 75,0 & 0,0 & 25,0 \\
\hline $\begin{array}{l}\text { Empresa em que possua normas de trabalho rígidas e definidas, } \\
\text { mas que ofereça estabilidade financeira. }\end{array}$ & 0,0 & 0,0 & 0,0 & 50,0 & 50,0 \\
\hline Total & 100 & 100 & 100 & 100 & 100 \\
\hline
\end{tabular}

Fonte: elaborada pelo autor, com base nos dados da pesquisa (2018)

Observações: os percentuais foram calculados sobre o total de observações de cada coluna, entre os graus 1 a 5 , sendo o grau 1 o de menor importância e o grau 5, de maior importância.

Analisando os fatores de motivação no ambiente de trabalho das pessoas que fazem parte da geração $X$, de acordo com a Tabela 4, observa-se que o "Ambiente de trabalho prazeroso e inovador, no qual possa expor suas ideias e oportunidades de testá-las" é considerado como o fator de maior importância. Outro fator de relativa importância é o relacionado com "Prestígio por ocupar um bom cargo numa empresa renomada e conhecida por todos". Os demais fatores de motivação desta geração foram considerados como de menor importância. No entanto, cabe salientar que as análises, na presente pesquisa, a respeito da geração $X$ não são conclusivas, por ter apenas quatro respondentes.

Referente aos fatores de motivação e à influência por ordem de importância para a geração Y, conforme a Tabela 5, nota-se que "Ambiente de trabalho prazeroso e inovador, no qual possa expor suas ideias e oportunidades de testá-las" ocupa a primeira posição como fator de maior importância, em grau 5, com 37,1\%, seguido com proximidade por "Uma ótima remuneração, que aumente seu poder de compra", com 36,3\%. Em terceiro lugar, está "Prestígio por ocupar um bom cargo numa empresa renomada e conhecida por todos", com 14,5\%. Já em quarto, o fator "Para mim a motivação é intrínseca, fatores externos não me influenciam", com $8,1 \%$, e em último lugar, com $4 \%$, "Empresa em que possua normas de trabalho rígidas e definidas, mas que ofereça estabilidade financeira". 
Tabela 5 - Influência por ordem de importância de fatores na motivação para os respondentes da geração $Y$, em percentual

\begin{tabular}{|c|c|c|c|c|c|}
\hline \multirow{3}{*}{$\begin{array}{l}\text { Geração Y } \\
\text { Fatores de influência na motivação }\end{array}$} & \multicolumn{5}{|c|}{ Grau de importância } \\
\hline & \multicolumn{3}{|c|}{ Maior } & \multicolumn{2}{|c|}{ Menor } \\
\hline & 5 & 4 & 3 & 2 & 1 \\
\hline $\begin{array}{l}\text { Ambiente de trabalho prazeroso e inovador, no qual possa } \\
\text { expor suas ideias e oportunidades de testá-las. }\end{array}$ & 37,1 & 27,4 & 21,0 & 11,3 & 9,7 \\
\hline Uma ótima remuneração, que aumente seu poder de compra. & 36,3 & 22,6 & 21,8 & 10,5 & 7,3 \\
\hline $\begin{array}{l}\text { Prestígio por ocupar um bom cargo numa empresa renomada e } \\
\text { conhecida por todos }\end{array}$ & 14,5 & 29,0 & 31,5 & 17,7 & 10,5 \\
\hline $\begin{array}{l}\text { Para mim a motivação é intrínseca, fatores externos não me } \\
\text { influenciam. }\end{array}$ & 8,1 & 10,5 & 13,7 & 24,2 & 41,1 \\
\hline $\begin{array}{l}\text { Empresa em que possua normas de trabalho rígidas e definidas, } \\
\text { mas que ofereça estabilidade financeira. }\end{array}$ & 4,0 & 10,5 & 12,1 & 36,3 & 31,5 \\
\hline Total & 100 & 100 & 100 & 100 & 100 \\
\hline
\end{tabular}

Fonte: elaborada pelo autor, com base nos dados da pesquisa (2018)

Observações: os percentuais foram calculados sobre o total de observações de cada coluna, entre os graus 1 a 5 , sendo o grau 1 o de menor importância e o grau 5, de maior importância.

Ao analisar os resultados dos respondentes da geração $Z$, apresentados na Tabela 6, visualiza-se que o fator "Ambiente de trabalho prazeroso e inovador, no qual possa expor suas ideias e oportunidades de testá-las" foi considerado como o de maior importância, em grau 5, com 35,7\%, seguido de "Uma ótima remuneração, que aumente seu poder de compra", com 32,1\%, e, em terceiro lugar, "Prestígio por ocupar um bom cargo numa empresa renomada e conhecida por todos", $\operatorname{com} 20,5 \%$, obtendo a maior nota para este fator em grau de influência 5 entre os três grupos geracionais respondentes. Em quarto lugar como fator de influência na motivação, está "Para mim a motivação é intrínseca, fatores externos não me influenciam", com 7,1\%, e como fator de menor influência, em grau 5, está "Empresa em que possua normas de trabalho rígidas e definidas, mas que ofereça estabilidade financeira", $\operatorname{com} 4,5 \%$. 
Tabela 6 - Influência por ordem de importância de fatores na motivação para os respondentes da geração $Z$, em percentual

\begin{tabular}{l|c|c|c|c|c}
\hline \multirow{2}{*}{ Geração Z } & \multicolumn{5}{c}{ Grau de importância } \\
\cline { 3 - 7 } & Maior & $\mathbf{4}$ & $\mathbf{4}$ & $\mathbf{2}$ & $\mathbf{1}$ \\
\hline Fatores de influência na motivação & 35,7 & 17,9 & 33,0 & 9,8 & 4,5 \\
\hline $\begin{array}{l}\text { Ambiente de trabalho prazeroso e inovador, no qual possa } \\
\text { expor suas ideias e oportunidades de testá-las. }\end{array}$ & 32,1 & 29,5 & 21,4 & 10,7 & 3,6 \\
\hline Uma ótima remuneração, que aumente seu poder de compra. & 20,5 & 29,5 & 25,0 & 13,4 & 11,6 \\
\hline $\begin{array}{l}\text { Prestígio por ocupar um bom cargo numa empresa renomada e } \\
\text { conhecida por todos. }\end{array}$ & 7,1 & 7,1 & 12,5 & 18,8 & 57,1 \\
\hline $\begin{array}{l}\text { Para mim a motivação é intrínseca, fatores externos não me } \\
\text { influenciam. }\end{array}$ & 4,5 & 16,1 & 8,0 & 47,3 & 23,2 \\
\hline $\begin{array}{l}\text { Empresa em que possua normas de trabalho rígidas e definidas, } \\
\text { mas que ofereça estabilidade financeira. }\end{array}$ & 100 & 100 & 100 & 100 & 100 \\
\hline Total
\end{tabular}

Fonte: elaborada pelo autor, com base nos dados da pesquisa (2018)

Observações: os percentuais foram calculados sobre o total de observações de cada coluna, entre os graus 1 a 5, sendo o grau 1 o de menor importância e o grau 5, de maior importância.

Após análise das Tabelas 4, 5 e 6, conclui-se que as empresas devem estar atentas ao ambiente de trabalho oferecido aos seus colaboradores que pertencem aos grupos geracionais pesquisados, visto que foi o fator apontado como de maior importância, em grau 5, para a motivação no ambiente organizacional. Porém, considera-se que a importância deste fator para as gerações $\mathrm{Y}$ e $\mathrm{Z}$ é relativa, por não apresentar uma larga diferença para o segundo fator citado, diferentemente da geração $X$, na qual a diferença é relevante. Sabe-se que este fator pode ser controlado, de certa forma, por ações planejadas pelos gestores e, também, pela área de recursos humanos, as quais devem estar de acordo com os objetivos de cada organização.

\section{CONSIDERAÇÕES FINAIS}

A motivação dos colaboradores é, para muitas empresas, um tema de suma relevância, pois para alcançarem seus objetivos principais, devem possuir equipes que trabalhem motivadas. Com isso, surge a necessidade de estudar os fatores que influenciam na motivação das três principais gerações atuantes no cenário das organizações atualmente, que são as gerações $\mathrm{X}, \mathrm{Y}$ e $Z$. Desta forma, levará maior vantagem as empresas que estiverem atentas aos fatores que motivam os indivíduos a se manterem conectados com os objetivos da organização.

Considerando que todos os objetivos específicos da pesquisa foram respondidos por meio da apresentação dos resultados, conclui-se que o objetivo geral estabelecido foi atingido, com destaque para a identificação do fator "Ambiente de trabalho prazeroso e inovador, no qual possa expor suas ideias e 
oportunidades de testá-las" como o de maior importância para as três gerações pesquisadas. Portanto, espera-se que o resultado deste estudo possa colaborar com as empresas da região, facilitando os processos de tomada de decisão, de acordo com as características de motivação de cada grupo geracional existente em seu cenário organizacional.

\section{REFERÊNCIAS}

ABRANTES, J. Pedagogia empresarial nas organizações que aprendem. 2. ed. Rio de Janeiro: Wak, 2012.

ARAUJO, L. C. G. Gestão de pessoas: edição compacta. São Paulo: Atlas, 2010.

BANOV, M. R. Psicologia no gerenciamento de pessoas. 3. ed. São Paulo: Atlas, 2013.

BARBIERI, U. F. Gestão de pessoas nas organizações: o talento humano na sociedade da informação. São Paulo: Atlas, 2014.

BERGAMINI, C. W. Motivação nas organizações. 5. ed. São Paulo: Atlas, 2008.

CHEMIN. B. F. Manual da Univates para trabalhos acadêmicos: planejamento, elaboração e apresentação. 3. ed. Lajeado, RS: Univates, 2015.

GIL, A. C. Métodos e técnicas de pesquisa social. 6. ed. São Paulo: Atlas, 2012.

LAPOLLI, E. M. Gestão de pessoas em organizações empreendedoras. Florianópolis: Pandion, 2010.

MALHOTRA, N. K. Pesquisa de marketing: uma orientação aplicada. 6. ed. Porto Alegre: Bookman, 2012.

MARRAS, J. P. Administração de recursos humanos: do operacional ao estratégico. 14. ed. São Paulo: Saraiva, 2011.

MASCARENHAS, S. A. Metodologia científica. São Paulo: Pearson Education do Brasil, 2012. E-book. Disponível em: http:/ / www.univates.br/biblioteca>. Acesso em: 28 mai. 2018.

MAXIMIANO, A. C. A. Teoria geral da administração: da revolução urbana à revolução digital. 8. ed. São Paulo: Atlas, 2017. E-book. Disponível em: <http:/ /www. univates.br/biblioteca>. Acesso em: 05 jun. 2018.

NASCIMENTO, N. M. et al. O estudo das gerações e a inteligência competitiva em ambientes organizacionais. Revista Perspectivas em Gestão \& Conhecimento, João Pessoa, v. 6, n. esp., p. 16-28, 2016. Disponível em: <http:/ / periodicos.ufpb.br/ojs/ index.php/pgc/article/view/27381>. Acesso em: 05 jun. 2018. 
OLIVEIRA, S. Jovens para sempre: como entender os conflitos de gerações. São Paulo: Integrare Editora, 2012.

ROBBINS, S. P. Comportamento organizacional. 14. ed. São Paulo: Pearson Prentice Hall, 2010.

SANTOS, G. E. O. Cálculo amostral: calculadora on-line. 2018. Disponível em: <http:/ / www.calculoamostral.vai.la>. Acesso em 24 out. 2018.

VELOSO, E. F. R. et al. Gestão de carreiras e crescimento profissional. Revista Brasileira de Orientação Profissional, Florianópolis, v. 12, n. 1, p. 61-72, 2011. Disponível em: <http:/ / pepsic.bvs-psi.org.br/rbop>. Acesso em: 03 mai. 2018.

VELOSO, E. F. R.; DUTRA, J. S.; NAKATA, L. E. Percepção sobre carreiras inteligentes: diferenças entre as gerações $Y, X$ e baby boomers. In: ENANPAD, 32, 2008. Rio de Janeiro. Anais... Rio de Janeiro, 2008. Disponível em: <https:/ /www. sciencedirect.com/science/ article/pii/S1809227616300108?via\%3Dihub>. Acesso em: 07 mai. 2018. 